\title{
Are certain foods addictive?
}

\author{
Adrian Meule ${ }^{1,2}$ * \\ 1 Department of Psychology I, Institute of Psychology, University of Würzburg, Würzburg, Germany \\ 2 Hospital for Child and Adolescent Psychiatry, LWL University Hospital of the Ruhr-University Bochum, Hamm, Germany \\ ${ }^{*}$ Correspondence: adrian.meule@uni-wuerzburg.de \\ Edited by: \\ Marco Diana, University of Sassari, Italy \\ Reviewed by: \\ Valentina Bassareo, University of Cagliari, Italy
}

Keywords: food addiction, Yale Food Addiction Scale, obesity, binge eating disorder, bulimia nervosa

\section{A commentary on}

Lifestyle medicine: the importance of firm grounding on evidence

by Rippe JM. Am J Lifestyle Med (2014)

doi:10.1177/1559827613520527

In a recent article (1), Dr. Rippe highlights that lifestyle medicine practitioners need to ground their recommendations on sound scientific evidence and that this is complicated by the fact that scientific information is often distorted and conjecture is sometimes confused with proof. This includes, for example, that associations between variables found in crosssectional studies are presented as causal relationships or that associations between variables found in epidemiological studies are often confounded by important third variables.

The author illustrates several examples of findings that are often misinterpreted and presented as true facts, although existing evidence needs to be critically evaluated. Those include the notions that (a) sugar causes obesity, (b) certain foods are addictive, (c) certain foods cause cancer, (d) exercise is not effective for weight loss, and that (e) there is a causal link between sugar consumption and diabetes.

I think that the author makes an important point in arguing that scientific evidence often is distorted by researchers or the media and that researchers and practitioners in the field of health behaviors continuously need to take care of scrutinizing research findings. Although I agree with most of the statements made in that article, I also think that some of them on the current concept of food addiction warrant a more in-depth discussion.

\section{APPROPRIATENESS OF ANIMAL MODELS}

Firstly, it is stated that "much of the argument related to food and addiction is based on [...] animal data" and that those models "may be poorly mimicked in human beings when it comes to food consumption." Presumably, the author refers to paradigms that show addiction-like consumption of sugar and neurobiological changes after several weeks of intermittent access to sugar (2). In these studies, rodents are, for example, food deprived for $12 \mathrm{~h}$ and then have access to lab chow or sugar for $12 \mathrm{~h}$. These paradigms are often criticized for being artificial and, thus, to have low value for making inferences about a possible sugar addiction in humans.

However, I would argue that these paradigms match quite well to the eating styles of some individuals. For example, individuals with bulimia nervosa (BN) engage in binge eating, but undereat on non-binge meals $(3,4)$. That is, food intake may be restricted throughout the day, followed by a binge episode (which usually includes high-calorie, e.g., high-sugar, foods) in the evening. The same eating topography may be seen in other weight-concerned individuals who try to restrict their food intake ["restrained eaters" (5)], although not exhibiting fullblown binge episodes. To summarize, animal models are indeed an important part of the food addiction hypothesis and human studies are lacking to support some of the results found in those studies. Nevertheless, the paradigm of intermittent access to food may parallel eating topography of some individuals with restrained or disordered eating behavior.

\section{EVIDENCE FOR FOOD ADDICTION BASED ON DSM-5}

Secondly, it is argued that "there is very little evidence for food addiction" based on the DSM-5 criteria for substance use disorder (SUD). Most articles in which the concept of food addiction is discussed refer to the substance dependence criteria in DSM-IV. In 2013, the DSM-5 was published and diagnostic criteria for SUDs now include 4 additional symptoms [11 symptoms in total (6)].

To the best of my knowledge, only one study has examined the new DSM-5 criteria in relation to eating behavior yet. In that study (7), a semi-structured interview was conducted, responses of which were qualitatively analyzed. Results showed that obese participants with binge eating disorder (BED), and to a lesser extent also those without BED, met the full criteria for SUD. Although participants rarely met three of the four new criteria, most of them met the new criterion of craving, or a strong desire or urge to use the substance. Admittedly, findings of this study should not be overinterpreted as the validity of the semi-structured interview is questionable and sample size was small. Undoubtedly, future studies are urgently needed that examine if the new DSM-5 SUD criteria can be translated to eating behavior and if those criteria are met by individuals who engage in over eating or binge eating [for a more detailed discussion (see Meule and Gearhardt, submitted)]. However, dismissing the appropriateness of the new DSM- 5 criteria with regard to food addiction in the first place seems unfair.

\section{FOOD ADDICTION DIAGNOSES IN DIFFERENT WEIGHT CATEGORIES}

Thirdly, the author suggests that "the Yale Food Addiction Scale [(YFAS) Ref. (8)] 
criteria may not be appropriate for diagnosing food 'addiction"' based on the fact that most obese people do not meet those criteria, but a substantial portion of underweight and normal-weight subjects do. Indeed, studies using this scale found prevalence rates of food addiction of about $5-10 \%$ in community or student samples and about $15-25 \%$ in obese samples (9, 10). In morbidly obese individuals or individuals with $\mathrm{BED}$, prevalence rates range between approximately 30 and 50\% $(9,10)$.

However, why do these findings disprove the validity of the YFAS? In my opinion, it rather shows that body mass is a poor measure when talking about food addiction. In most cases, obesity is the consequence of modest daily excess of energy consumption over energy expenditure (11). In fact, the error in caloric balance in obese persons is on average $<0.0017 \%$ per year (12). Eating behavior in such individuals is certainly not comparable to an addiction but is rather related to eating styles such as grazing or mindless eating. Instead, addiction is much more comparable to binge eating such as in $\operatorname{BED}$ or $\mathrm{BN}(13,14)$ and this is exactly what is found using the YFAS (15, Meule et al., submitted). To conclude, the notion that food addiction may be responsible for the high prevalence rates of obesity and that obesity by itself represents an addictive behavior is outdated $(15,16)$ and the YFAS has contributed to these insights. Instead, food addiction is rather related to binge eating behaviors and the YFAS although it may not be perfect - appears to be a helpful assessment tool in this context.

\section{FOOD ADDICTION AND BRAIN IMAGING}

Fourthly, another argument is that "brain imaging studies [...] do not support an addiction model." This is based on a critical review by Ziauddeen and colleagues (16), which was, in turn, controversially discussed (17-19). Specifically, the authors found that brain imaging studies that involved presentation of food-cues in obese individuals with or without BED are inconsistent. Although brain activations in such studies are often related to prefrontal, limbic, or paralimbic areas, involvement of specific areas differs across studies. Furthermore, although there are similarities in brain responses to food and drugs, substantial differences have also been noted (20).

Nonetheless, common substrates were identified in meta-analyses (21). Inconsistencies in brain imaging studies are partly driven by the heterogeneity of the samples studied. Preferably, future studies that investigate the food addiction model should include individuals who actually receive a food addiction diagnosis (e.g., using the YFAS) and a control group of individuals who do not receive a food addiction diagnosis. Thus, it may be unjustified to conclude that neuroimaging studies do not support a food addiction model, as many of the existing studies were not specifically tailored to investigate this.

\section{NECESSITY AND POTENTIAL DOWNSIDES OF THE FOOD ADDICTION} MODEL

Finally, the author concludes that "much of the food-related pathology that is seen clinically can be explained and treated without invoking addiction, and in some cases using an addiction model may lead to further food-related pathology." The food addiction model surely involves the danger of possibly creating a new stigma $(22,23)$ or to move attention away from the individual's responsibility in weight regulation such as engaging in physical activity (24, 25). Moreover, current psychological treatments of BED are actually quite successful (26) and, thus, may not need to be adapted according to a food addiction model.

However, it has also been found that the concept of food addiction has a more positive public perception compared with alcohol or tobacco use and that the food addict label may be less vulnerable to public stigma than other addictions $(22,23$, 27). Moreover, case reports exist, which show that providing an addiction framework may be helpful for some individuals, for example, those struggling with overweight and diet failures $(28,29)$ or with eating disorders such as BN (30). Thus, the food addiction model may be beneficial in some instances and may not be necessary or has potential downsides in others. However, drawing straightforward conclusions is not possible yet.

\section{CONCLUSION}

The idea that some forms of overeating may represent an addictive behavior and that specific foods may have an addiction potential has been discussed in the scientific literature for decades (31). In the 2000s, scientific interest on food addiction has strongly increased in the light of the obesity pandemic and the rise of neuroimaging studies (32). Unfortunately, "this argument resonates strongly with the media and the public and has been perpetuated rather uncritically" (1) (p. 5). I unequivocally agree with the author that (a) media reports do not appropriately address the controversial concept of food addiction, (b) many findings from animal studies are not yet replicated in human studies, (c) obesity does not represent an addiction by itself, (d) brain imaging studies are inconsistent, and that (e) the necessity or potential downside of the food addiction concept in treatment or public health issues is still unclear. However, those are issues that will likely be addressed in future studies. Thus, it would be unjustified to dismiss the concept of food addiction based on limited data (18).

\section{REFERENCES}

1. Rippe JM. Lifestyle medicine: the importance of firm grounding on evidence. Am J Lifestyle Med (2014). doi:10.1177/1559827613520527

2. Avena NM, Rada P, Hoebel BG. Evidence for sugar addiction: behavioral and neurochemical effects of intermittent, excessive sugar intake. Neurosci Biobehav Rev (2008) 32:20-39. doi:10.1016/j. neubiorev.2007.04.019

3. Alpers GW, Tuschen-Caffier B. Energy and macronutrient intake in bulimia nervosa. Eat Behav (2004) 5:241-9. doi:10.1016/j.eatbeh.2004. 01.013

4. Heaner MK, Walsh BT. A history of the identification of the characteristic eating disturbances of bulimia nervosa, binge eating disorder and anorexia nervosa. Appetite (2013) 71:445-8. doi: 10.1016/j.appet.2013.06.001

5. Stroebe W. Restrained eating and the breakdown of self-regulation. In: Stroebe W, editor. Dieting, Overweight, and Obesity - Self-Regulation in a Food-Rich Environment. Washington, DC: American Psychological Association (2008). p. 115-39.

6. American Psychiatric Association. Diagnostic and Statistical Manual of Mental Disorders. 5th ed. Washington, DC: American Psychiatric Association (2013).

7. Curtis C, Davis C. A qualitative study of binge eating and obesity from an addiction perspective. Eat Disord (2014) 22:19-32. doi:10.1080/10640266. 2014.857515

8. Gearhardt AN, Corbin WR, Brownell KD. Preliminary validation of the Yale food addiction scale. Appetite (2009) 52:430-6. doi:10.1016/j. appet.2008.12.003 
9. Meule A. Food addiction and body-mass-index: a non-linear relationship. Med Hypotheses (2012) 79:508-11. doi:10.1016/j.mehy.2012.07.005

10. Meule A. How prevalent is "food addiction"? Front Psychiatry (2011) 2:61. doi:10.3389/fpsyt. 2011.00061

11. Rogers PJ. Obesity - is food addiction to blame? Addiction (2011) 106:1213-4. doi:10.1111/j.13600443.2011.03371.x

12. Stunkard A, Platte P. Obesity. In: Kazdin AE, editor. Encyclopedia of Psychology. (Vol. 5), Washington, DC: American Psychological Association (2000). p. $485-8$.

13. Gearhardt AN, White MA, Potenza MN. Binge eating disorder and food addiction. Curr Drug Abuse Rev (2011) 4:201-7. doi:10.2174/ 1874473711104030201

14. Umberg EN, Shader RI, Hsu LK, Greenblatt DJ. From disordered eating to addiction: the "food drug" in bulimia nervosa. J Clin Psychopharmacol (2012) 32:376-89. doi:10.1097/JCP. 0b013e318252464f

15. Davis C. Compulsive overeating as an addictive behavior: overlap between food addiction and binge eating disorder. Curr Obes Rep (2013) 2:171-8. doi:10.1007/s13679-013-0049-8

16. Ziauddeen H, Farooqi IS, Fletcher PC. Obesity and the brain: how convincing is the addiction model? Nat Rev Neurosci (2012) 13:279-86. doi:10.1038/ nrn3212

17. Ziauddeen H, Farooqi IS, Fletcher PC. Food addiction: is there a baby in the bathwater? Nat Rev Neurosci (2012) 13:514. doi:10.1038/nrn3212-c2

18. Avena NM, Gearhardt AN, Gold MS, Wang GJ, Potenza MN. Tossing the baby out with the bathwater after a brief rinse? The potential downside of dismissing food addiction based on limited data. Nat Rev Neurosci (2012) 13:514. doi:10.1038/ nrn3212-cl
19. Meule A, Kübler A. The translation of substance dependence criteria to food-related behaviors: different views and interpretations. Front Psychiatry (2012) 3:64. doi:10.3389/fpsyt.2012. 00064

20. Benton D. The plausibility of sugar addiction and its role in obesity and eating disorders. Clin Nutr (2010) 29:288-303. doi:10.1016/j.clnu.2009. 12.001

21. Tang DW, Fellows LK, Small DM, Dagher A. Food and drug cues activate similar brain regions: a meta-analysis of functional MRI studies. Physiol Behav (2012) 106:317-24. doi:10.1016/j.physbeh. 2012.03.009

22. DePierre JA, Puhl RM, Luedicke J. A new stigmatized identity? Comparisons of a "food addict" label with other stigmatized health conditions. Basic Appl Soc Psych (2013) 35:10-21. doi:10.1080/ 01973533.2012.746148

23. DePierre JA, Puhl RM, Luedicke J. Public perceptions of food addiction: a comparison with alcohol and tobacco. J Subst Use (2014) 19:1-6. doi:10.3109/14659891.2012.696771

24. Lee NM, Carter A, Owen N, Hall WD. The neurobiology of overeating. ЕMBO Rep (2012) 13:785-90. doi:10.1038/embor.2012.115

25. Lee NM, Lucke J, Hall WD, Meurk C, Boyle FM, Carter A. Public views on food addiction and obesity: implications for policy and treatment. PLoS One (2013) 8:e74836. doi:10.1371/journal.pone. 0074836

26. Vocks S, Tuschen-Caffier B, Pietrowsky R, Rustenbach SJ, Kersting A, Herpertz S. Metaanalysis of the effectiveness of psychological and pharmacological treatments of binge eating disorder. Int J Eat Disord (2010) 43:205-17. doi: 10.1002/eat.20696

27. Latner JD, Puhl RM, Murakami JM, O’Brien KS. Food addiction as a causal model of obesity.
Effects on stigma, blame, and perceived psychopathology. Appetite (2014) 77:79-84. doi:10. 1016/j.appet.2014.03.004

28. Avena NM, Talbott JR. Why Diets Fail (Because You're Addicted to Sugar). New York, NY: Ten Speed Press (2014).

29. Russel-Mayhew S, von Ranson KM, Masson PC. How does overeaters anonymous help its members? A qualitative analysis. Eur Eat Disord Rev (2010) 18:33-42. doi:10.1002/erv.966

30. Slive A, Young F. Bulimia as substance abuse: a metaphor for strategic treatment. J Strateg Syst Ther (1986) 5:71-84.

31. Randolph TG. The descriptive features of food addiction: addictive eating and drinking. Q J Stud Alcohol (1956) 17:198-224.

32. Gearhardt AN, Davis C, Kuschner R, Brownell KD. The addiction potential of hyperpalatable foods. Curr Drug Abuse Rev (2011) 4:140-5. doi:10.2174/ 1874473711104030140

Received: 12 March 2014; paper pending published: 24 March 2014; accepted: 25 March 2014; published online: 07 April 2014.

Citation: Meule A (2014) Are certain foods addictive? Front. Psychiatry 5:38. doi: 10.3389/fpsyt.2014.00038

This article was submitted to Addictive Disorders and Behavioral Dyscontrol, a section of the journal Frontiers in Psychiatry.

Copyright (c) 2014 Meule. This is an open-access article distributed under the terms of the Creative Commons Attribution License (CC BY). The use, distribution or reproduction in other forums is permitted, provided the original author(s) or licensor are credited and that the original publication in this journal is cited, in accordance with accepted academic practice. No use, distribution or reproduction is permitted which does not comply with these terms. 